\title{
Idiopathic Intracranial Hypertension: Changing Trends
}

\author{
${ }^{1}$ Ashok Kumar Gupta, ${ }^{2}$ Gopika Kalsotra, ${ }^{3}$ Anish Gupta, ${ }^{4}$ Vikas Saini, ${ }^{5}$ Vivek Lal \\ ${ }^{1}$ Professor and Head (Unit II), Department of Otolaryngology, Postgraduate Institute of Medical Education and Research, Chandigarh, India \\ ${ }^{2}$ Senior Resident, Department of Otolaryngology, Postgraduate Institute of Medical Education and Research, Chandigarh, India \\ ${ }^{3}$ Consultant, Department of ENT, Fortis Hospital, Mohali, Punjab, India \\ ${ }^{4}$ Assistant Professor, Department of Anesthesia, Postgraduate Institute of Medical Education and Research, Chandigarh, India \\ ${ }^{5}$ Professor, Department of Neurology, Postgraduate Institute of Medical Education and Research, Chandigarh, India
}

Correspondence: Ashok Kumar G upta, Professor and Head (Unit II), Department of Otolaryngology, P ostgraduate Institute of Medical Education and Research, Chandigarh, India, Phone: 01722756766, e-mail: drashokpgi@ hotmail.com

\begin{abstract}
Idiopathic intracranial hypertension (IIH) is a disorder of raised ICP without any obvious underlying brain pathology. Early intervention remains the key to success. The patients with BIH and vision threatening papilloedema should be taken up for optic nerve fenestration and the results are favorable in terms of visual outcome. The procedure is safe with few intraoperative or postoperative complications.
\end{abstract}

Keywords: Pseudotumor cerebri, BIH, Optic nerve fenestration.

\section{INTRODUCTION}

Idiopathic intracranial hypertension $(\mathrm{IIH})$ is a disorder characterized by el evated cerebrospinal fluid pressurewithout any known cause. In 1893, Q uincke reported the first case of $\mathrm{IIH}$ and described the entity as meningitis serosa. ${ }^{1}$ It was named pseudotumor cerebri in 1904 by Nonne. ${ }^{2}$ In 1955 , Foley coined the term benign intracranial hypertension. ${ }^{3}$ How ever, in view of high incidence of visual loss associated with papilledema, Corbett and Thompson ${ }^{4}$ substituted the adjective 'benign' with 'idiopathic' . Idiopathic intracranial hypertension denotes the condition of raised ICP without an obvious underlying brain pathological condition (and no evidence of venous thrombosis).

The diagnostic characteristics of this syndrome were first enumerated by Dandy in $1937 .{ }^{5}$ The modified Dandy criteria formulated by Smith in $1985^{6}$ include symptoms of increased ICP (headache, nausea, vomiting, transient visual obscurations, papilledema), no or fal se localizing neurological signs like abducens or facial palsies, an awake and alert patient, normal brain imaging results without evidence of dural sinus thrombosis, ICP of more than $250 \mathrm{~mm} \mathrm{H}_{2} \mathrm{O}$ with normal CSF findings, and no identifiable cause of increased ICP.

$\mathrm{IIH}$ occurs most commonly among obese women of child bearing age. The annual incidence of $\mathrm{IIH}$ is $0.9 / 100,000$ persons and 3.5/100,000 in women 15 to 44 years of age. The incidence increases to $13 / 100,000$ women of ages 20 to 44 years who are $10 \%$ above ideal body weight and 19 cases/100,000 women of ages 20 to 44 years who are obese ( $>20 \%$ above ideal body weight). ${ }^{7}$ The mean age at the time of diagnosis is approximately 30 years. $^{8}$ Female-tomale ratios are approximately $4.3: 1$ to $8: 1 .^{9}$ The incidence is 0.3 cases $/ 100,000$ men and increases to 1.5 cases $/ 100,000$ obese men. No racial predilection has been noted. I solated familial cases ${ }^{10,11}$ raise the possibility of a genetic relationship, but no linkage studies have been performed to date.

\section{Pathogenesis}

There are multiple theories proposed to explain the pathogenesis of $\mathrm{IIH}$.

A first possibility is increased CSF volume due to excess CSF production. B ut there is no clear evidence for elevated CSF production as an etiological factor in intracranial hypertension. ${ }^{12} \mathrm{~A}$ second possibility is increased cerebral blood volume or brain water content as proposed by Dandy ${ }^{5}$ and Foley. ${ }^{3}$ A ccording to a study by Sahs and J oynt, ${ }^{13}$ there was histological evidence of edema in brain biopsy specimens obtained at the time of subtemporal decompression for treatment of $\mathrm{IIH}$. M ore recent studies using magnetic resonance imaging demonstrated increased water apparent diffusion coefficients and increased white matter water signals. ${ }^{14,15}$

A third and most accepted possibility is reduction of CSF absorption secondary to increased sagittal sinus pressure. A recent study using pressure measurements during intracranial venography demonstrated elevated dural sinus pressures among patients with $\mathrm{IH}^{16}$ The final common pathway for increased ICP in IIH involves elevated venous pressure, leading to increased resistance to CSF absorption and subsequently increased ICP. Due to female 
preponderance, endocrinological dysfunction has been hypothesized to contribute to the disease. Obesity is a predisposing factor for IIH due to increased intraabdominal pressure leading to increased right heart filling pressure and subsequently increased central venous pressure and obesityassociated sleep apnea. W eight loss has been demonstrated to reduce papilledema and lower CSF pressures. ${ }^{17}$

\section{Clinical Presentation}

\section{Symptoms}

A Imost all the patients have headache ${ }^{18}$ which is typically generalized, episodic, throbbing, worse in the morning, aggravated by $V$ alsalva maneuvers and may be associated with neck, shoulder and arm pain. In addition, transient visual obscurations and diplopia are frequently seen. $V$ isual obscurations are episodes of transient blurred vision that usually last less than 30 seconds and are followed by visual recovery to baseline. Visual obscurations occur in about 30 to $68 \%$ of $\mathrm{IIH}$ patients. ${ }^{19}$ Pulsatile tinnitus is common and may be the initial complaint. ${ }^{20}$ The cause of tinnitus is turbulence resulting from higher-to-lower venous pressures around the jugular bulb. Other symptoms include numbness, incoordination, decreased smell, weakness and dizziness.

\section{Signs}

Papilledema (Fig. 1) is the cardinal sign of $\mathrm{IIH}$ and is seen in nearly all patients, but the absence of papilledema is thus, not a criteria of exclusion. ${ }^{21,22}$ Sixth nerve palsy, is seen in approximately $20 \%$ of cases resulting in horizontal diplopia. ${ }^{19,23}$ Seventh nerve palsy may also be observed. ${ }^{24}$

\section{Ophthalmoscopic Findings}

The hallmark of IIH is bilateral optic nerve head swelling. However, there have been numerous case reports of $\mathrm{IIH}$ without papilledema. ${ }^{21,22,25}$ Papilledema may be asymmetric or unilateral. Frisén has proposed a useful staging scheme

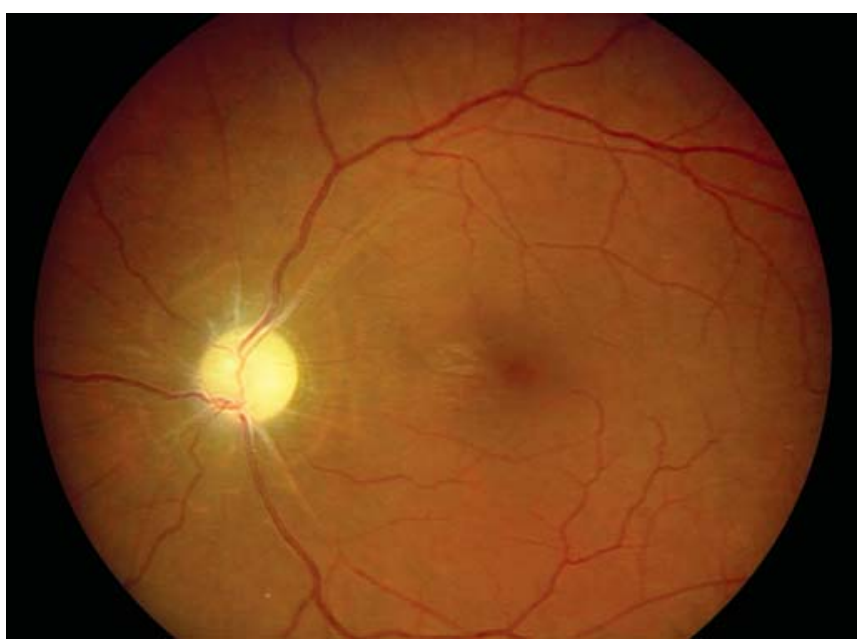

Fig. 1: Fundus showing papilledema for papilledema which has been modified recently. ${ }^{26} \mathrm{G}$ rade 0 represents a normal optic disk. Grade 1 is characterized by the presence of a C-shaped or reverse C-shaped halo of peripapillary edema obscuring the retina adjacent to the optic disk. In grade 2, the C-shaped halo becomes circumferential. In grade 3, there is complete obscuration of at least one major vessel as it leaves the optic disk. With the increased optic in grade 4 there is complete obscuration of at least one major vessel on the optic disk. Grade 5 is characterized by grade 4 and at least partial obscuration of all major vessels leaving or on the disk.

\section{Perimetry}

Visual field loss occurs in almost all cases of IIH. A prospective study of $\mathrm{IIH}$ found visual loss in at least one eye in $96 \%$ of patients with Goldmann perimetry and in $92 \%$ with automated perimetry. 8,27 In $30 \%$ of cases visual loss is mild and goes unnoticed by the patient but serves as a marker to guide therapy. ${ }^{8}$ The loss of visual field is gradually progressive and may lead to blindness in about $5 \%$ of cases. The earliest visual field defect in IIH is often an inferior nasal step defect followed by peripheral nasal loss. A rcuate defects may appear next followed by a gradual depression of the entire field, most pronounced peripherally.

\section{Imaging Findings}

Normal imaging is a prerequisite for the correct diagnosis of IIH. Computed tomographic scans demonstrate undilated ventricles, enlarged optic nerve sheaths and empty sella syndrome. ${ }^{28,29}$ The M RI findings in IIH include a partially empty sella (Fig. 2), flattening of the posterior sclera, dilation and tortuosity of the optic nerve sheath (Fig. 3), and sometimes gadolinium enhancement of the optic disk. ${ }^{30,31}$ However, the findings are often too subtle and unremarkable to allow the diagnosis of increased ICP on the basis of M RI scans alone. Ophthalmoscopic examinations must be

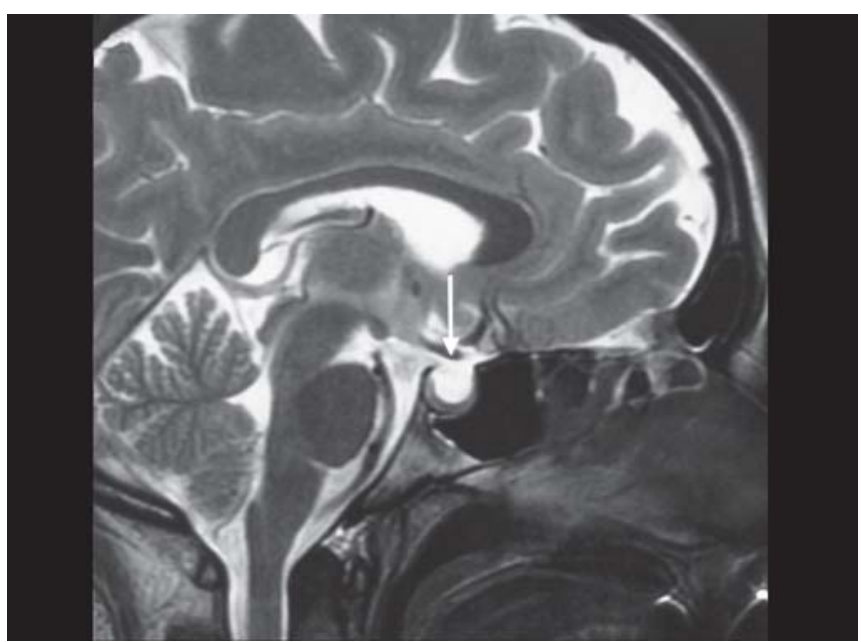

Fig. 2: MRI showing empty sella 
performed to identify patients with increased ICP. M agnetic resonance venography (MRV) is the procedure of choice for diagnosis of dural venous sinus thrombosis in $\mathrm{BIH}$. Limited intracranial thrombosis, typically of the transverse sinus can present with BIH without local izing neurological signs. It is important to establish the presence or otherwise of clot in the venous sinuses as steroid treatment in this situation may exacerbate the condition.

\section{Lumbar Puncture Findings}

Increased intracranial pressure with normal CSF chemical and cellular analysis confirms the diagnosis of $\mathrm{IH}$. A pressure of greater than $250 \mathrm{~mm} \mathrm{H}_{2} \mathrm{O}$ (measured with the patient relaxed, in the lateral decubitus position) is one of the modified Dandy criteria. However, it is important to recognize that $42 \%$ of asymptomatic obese female patients have opening pressures of greater than $250 \mathrm{~mm} \mathrm{H}_{2} \mathrm{O}$. Conversely, a pressure of less than $250 \mathrm{~mm} \mathrm{H}_{2} \mathrm{O}$ is consistent with papilledema in some cases. ICP monitoring with intraparenchymal pressure monitors may occasionally be necessary if diagnostic doubt persists.

\section{Clinical Course}

The most devastating sequela of $\mathrm{IIH}$ is permanent visual impairment. The mechanism of visual loss is high cerebrospinal fluid pressure which is reflected along trabeculations in the subarachnoid space of the optic nerve sheath. This results in a disturbance of the pressure gradient across the optic nerve head. There is resultant axoplasmic flow stasis, intraaxonal swelling and compression of small arterioles resulting in intraneuronal ischemic damage to the optic nerve. V isual loss is usually slowly progressive and vision should be monitored closely and surgical intervention should be performed before it is too late. B ut patients with severe papilledema, vision can decline rapidly in a matter of hours, creating the potential for a neurological emergency.

Snellen acuity and the visual evoked potential are insensitive methods to detect visual loss in $\mathrm{IIH} .{ }^{4}$ R epeated measurements of cerebrospinal fluid pressure is inconclusive as it fluctuates throughout the day and does not correlate well with the clinical state. Patients with $\mathrm{IIH}$ should be followed with quantitative perimetry (automated perimetry) and serial stereo fundus photos. In few cases, IIH is a selflimiting condition that spontaneously remits before significant damage to the optic nerve. ${ }^{32}$

\section{Treatment}

The goals of treatment are symptom, relief and preservation of vision. The various treatment modalities include medical management and surgical management. M ost cases respond to nonsurgical management.

\section{Medical Therapy}

Medical treatment is aimed at lowering of intracranial pressure and treating symptoms directly, such as headache. The various modalities include:

Weight loss: W eight loss has been found to be effective for patients with papilledema resulting from $\mathrm{IIH}$. Reversal of papill edema has been documented with modest degrees of weight loss in the range of 5 to $10 \%$ total body weight. ${ }^{33,34}$ D rastic resolution of symptoms was seen in morbidly obese women with IIH who were treated with gastric weight reduction surgery. ${ }^{35}$ Thus, professional dietary counseling and weight loss programs should be recommended in these patients. Institution of a low salt diet and mild fluid restriction also appear to be beneficial for many $\mathrm{IIH}$ patients.

Diuretics: Carbonic anhydrase inhibitors (e.g. acetazolamide) are the only effective medications for treatment of papilledema. A cetazolamide was originally demonstrated by Rubin et $\mathrm{al}^{36}$ to decrease CSF production. M CCarthy and Reed $^{37}$ showed acetazolamide decreases CSF flow only if over $99.5 \%$ of choroid plexus carbonic anhydrase was inhibited. It is generally started in a dose of $1 / 2$ to $1 \mathrm{gm}$ a day in divided doses and gradually increased until either symptoms and signs regress, side effects become intolerable or a dose of 3 to $4 \mathrm{gm}$ per day is reached. M ost patients appear to respond in the 1 to $2 \mathrm{gm}$ per day. ${ }^{38}$ It should be avoided in pregnant women due to its teratogenic effects. Side effects include tingling in the fingers, toes, and perioral region, renal stones, metabolic acidosis and aplastic anemia. Topiramate has also been used to treat $\mathrm{IIH}$ and has been found to be comparable to acetazolamide. ${ }^{39}$ Furosemide has little effect on CSF production and may be used for patients who cannot tolerate acetazol amide. ${ }^{40}$

Corticoster oids: The role of corticosteroids in the treatment of papilledema is controversial. The side effects of weight gain, striae and acne are especially unfortunate for these already obese patients. A short course of high-dose corticosteroid therapy may be hel pful for patients with acute visual loss resulting from fulminant papill edema. ${ }^{40} \mathrm{U}$ se of long-term steroids to treat IIH has largely been abandoned.

Serial lumbar punctures: These can be used as an al ternative to surgery for patients with papilledema that cannot be controlled medically. Lumbar puncture has only a shortlived effect on CSF pressure with a return of pressure to pretap level after only 82 minutes. ${ }^{41} \mathrm{~L}$ umbar puncture and drainage of a large volume of CSF are useful emergency measures for patients with severe papill edema and sudden extinction of vision.

\section{Surgical Therapy}

Surgical management is indicated in those with deteriorating visual function and/or severe incapacitating headaches 
interfering with daily activities despite vigorous medical management. The surgical forms of therapy now used are various shunting and decompression procedures including CSF shunting procedures and optic nerve sheath fenestration.

\section{CSF Shunting Procedures}

$\checkmark$ arious shunting procedures have been employed for the treatment of idiopathic intracranial hypertension, such as lumbar subarachnoid-peritoneal shunts, ventriculoatrial, ventriculojugular and ventriculoperitoneal shunts. LPS effectively lowers intraventricular pressure and relieves headaches and papilledema. But, it is fraught with problems. Shunt obstruction and low pressure headaches are the most common complications. Other complications include acquired cerebellar tonsillar herniation, syringomyelia, lumbar radiculopathy and infection.

Johnston et al ${ }^{42}$ published a major review of 134 cases of IIH treated between 1942 and 1979, with a mean followup period of 11.6 years. Fourteen patients received shunts (six VP shunts and eight LP shunts). Of the six patients who received $V P$ shunts, there was resolution of all symptoms within 6 months in four patients. One patient developed a shunt obstruction that necessitated revision, and another patient developed a shunt infection that necessitated removal. of the eight patients who received LP shunts, there was improvement in all within 1 month. One patient experienced a shunt infection, and one patient exhibited severe low-pressure symptoms as a result of overshunting. In a follow-up study by the same author, ${ }^{43}$ 36 patients required a total of 86 shunting procedures, with a complication rate of $52 \%$ and a failure rate of $48 \%$; the lowest revision and complication rates were associated with LP shunts.

A multicenter review of the outcomes of shunting for 37 patients was performed in the late 1980s by Rosenberg et al. ${ }^{44} \mathrm{~T}$ hirty-seven patients received a total of $73 \mathrm{~L} P$ shunts and nine V P shunts, and only 14 patients remained 'cured' after a single surgical procedure. $64 \%$ of shunts lasted less than 6 months, with shunt failure (55\%) and low-pressure headaches $(21 \%)$ being the most common reasons for reoperation. The vision of most patients either improved (13 patients) or stabilized (13 patients) postoperatively. Eggenberger et $\mathrm{al}^{45}$ conducted a retrospective study of 27 patients with $\mathrm{IIH}$, who were monitored for a median of 47 months after shunting. Vision improved or remained the same for all patients, and headaches improved for all patients. There were no serious complications, except for shunt failure $56 \%$ required shunt revision. The average number of revisions per patient was 2.4 , with one revision being performed every 2.6 years. The authors concluded that $L P$ shunting was a satisfactory treatment for the majority of patients.
For patients with repeated LP shunt obstructions, the option of VP shunting should be considered. First, although the technique is more invasive, the long-term outcomes may be better. ${ }^{46}$ Second, technical innovations in stereotactic surgery enable accurate targeting of the lateral ventricle.

Third, V P shunting may facilitate noninvasive assessment of shunt function, because it provides a reservoir for isotope shunt function testing. ${ }^{47}$

\section{Optic Nerve Sheath Fenestration}

Optic nerve sheath fenestration, which was introduced by de W ecker, ${ }^{48}$ was the first treatment devised for the surgical relief of papilledema. The operation involved insertion of a guarded neurotome into the orbit to slit the optic nerve sheath via a conjunctival incision. Since then, the procedure was performed by a few surgeons. ${ }^{48-50}$ The failure rate associated with LP shunting renewed enthusiasm for optic nerve sheath fenestration in the 1980s. In 1988, three major reports appeared in the world literature, describing the outcomes of optic nerve sheath fenestration for treatment of $\mathrm{IIH}$ in large series of patients. ${ }^{51-53}$ The results were surprisingly good; the procedure seemed to provide effective treatment of papilledema and maintained or improved visual acuity for 85 to $100 \%$ of patients. However, the follow-up periods were short in those studies.

Optic nerve sheath fenestration is currently the preferred treatment for the patients with progressive visual loss with mild or easily controlled headaches, although over $50 \%$ of patients with the procedure gain adequate headache control. The mechanism by which it works is unclear. There are 3 possibilities: (1) a filtering effect causing localized CSF reduction and improved peripapillary circulation, (2) a generalized reduction in ICP, (3) closure of the subarachnoid space in the retrolaminar optic nerve by scarring thus, protecting the optic nerve head from CSF pressure (Friedman).

In a study Spoor et $\mathrm{al}^{54}$ of 53 patients (101 eyes), optic nerve sheath fenestration improved vision in 69 eyes with acute papilledema and 10 eyes with chronic papilledema. In another study by Spoor and M CHenry ${ }^{55}$ described the outcomes of optic nerve sheath fenestration for 75 eyes of 54 patients with IIH. There was initial improvement in visual function in all eyes but 24 eyes (32\%) required repeat optic nerve sheath fenestration due to deterioration of vision which was detected 10.4 months after surgery, and $25 \%$ of eyes continued to lose vision even after repeat surgery. In a study by Sergott et al ${ }^{56}$ in 1989, there was improved visual function in 12 of 14 patients who were treated with optic nerve sheath fenestration.

Occasionally, there were catastrophic visual complications in the perioperative period. The incidence of vision loss was three cases/115 patients (2.6\%) in one 


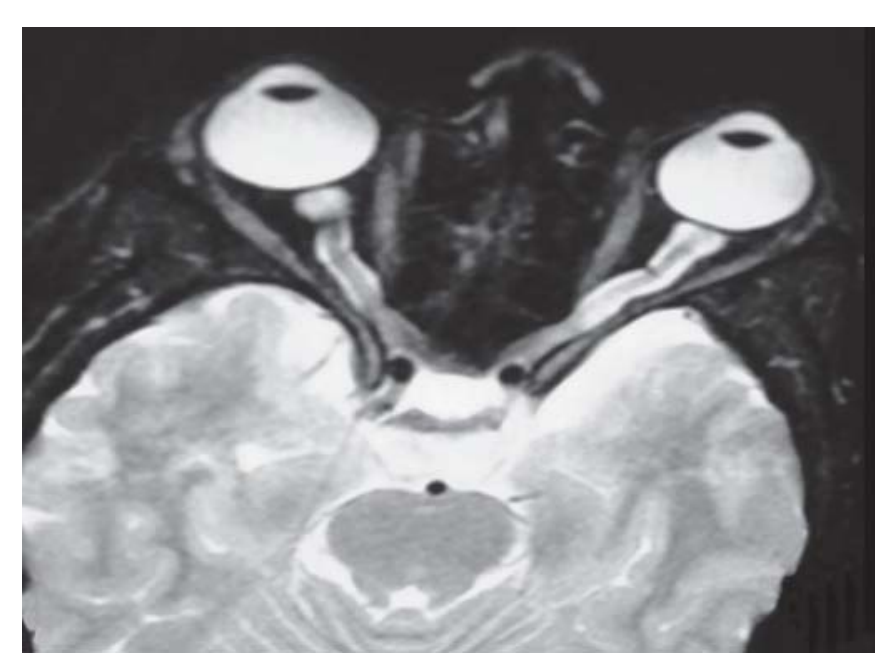

Fig. 3: MRI showing dilation and tortuous of the optic nerve sheath

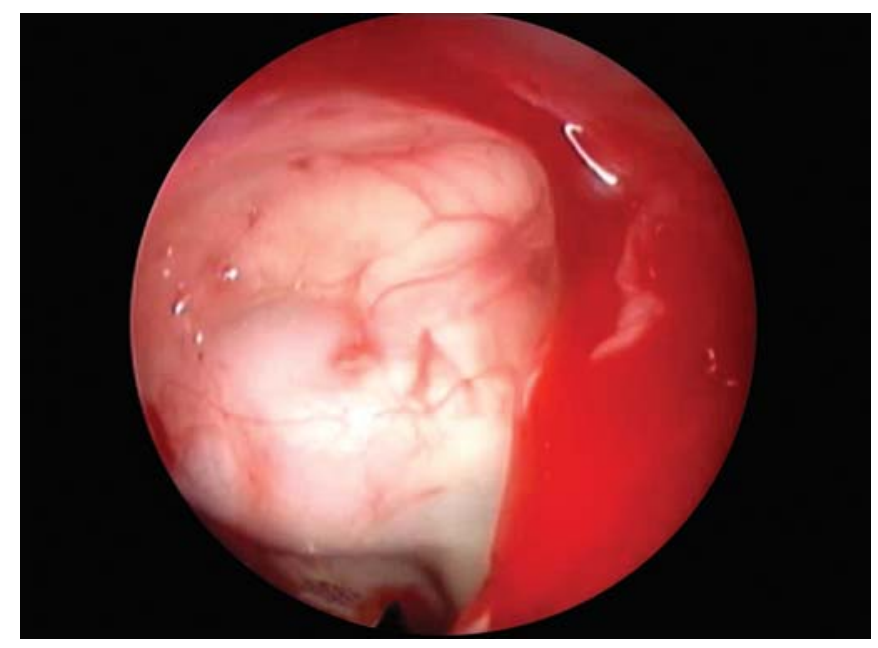

Fig. 4: Operative photograph showing sphenoidotomy

study. ${ }^{56} \mathrm{~A}$ nother study reported postoperative blindness for three of 200 patients $(1.5 \%),{ }^{57}$ Other complications include vascular compromise $(11 \%$, central retinal artery occlusion, branch retinal artery occlusion, or outer retinal ischemia), transient ocular motility disturbances $(29 \%)$ and papillary dysfunction $(11 \%))^{58}$

Endoscopic endonasal optic nerve fenestration was first advocated by Gupta $\mathrm{A} \mathrm{K}$ et al, ${ }^{59}$ and is a safe, minimally invasive, and extremely effective procedure for the management of $\mathrm{IIH}$. In their prospective study on 18 patients, 17 had improvement in vision postoperatively (94.5\% success rate). Fifteen patients had visual deterioration in the other eye as well, and of these, 12 had improvement, obviating the need for surgery on the other side. The surgical procedure includes endoscopic sphenoidotomy (Fig. 4) and decompression of posterior third of orbit and optic nerve (Fig. 5). L ater two windows are created by incising optic sheath (Fig. 6); one at the level of annulus of Zinn and the other in the optic nerve. Complications were minimal and in the form of synechiae in two of the cases.

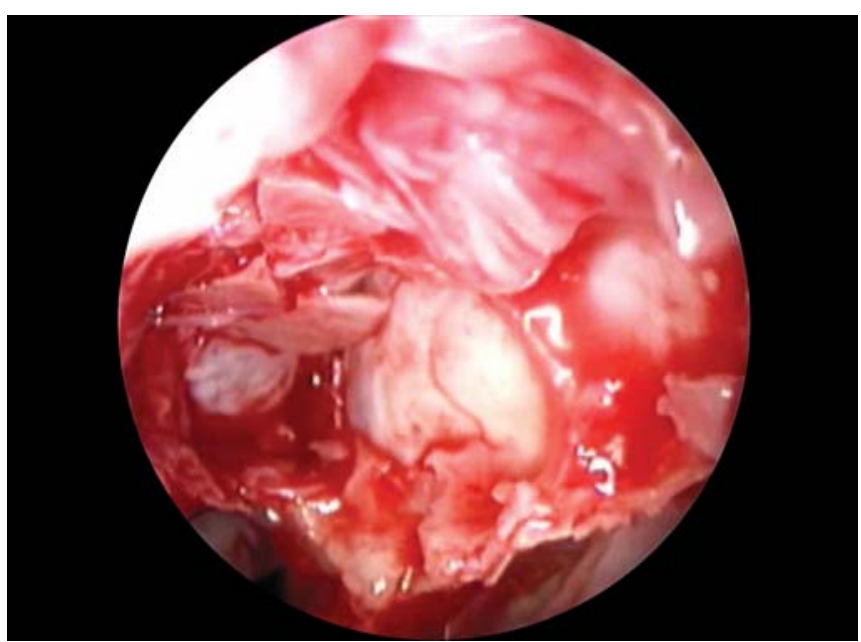

Fig. 5: Operative photograph showing decompression of posterior third of orbit and optic nerve

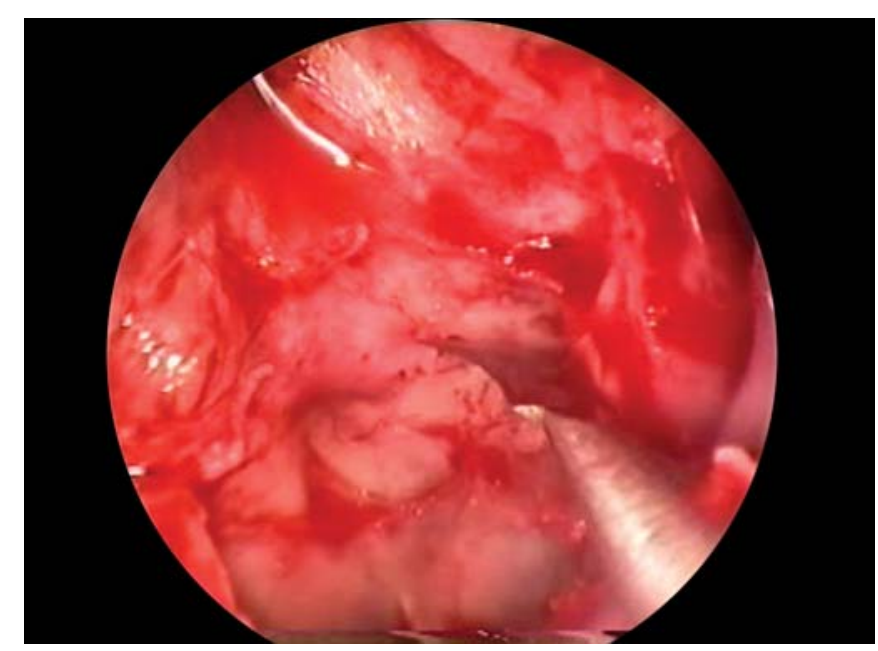

Fig. 6: Operative photograph showing incision over optic sheath

The key to success with ON SF is early intervention and the appropriate expertize. Undoubtedly, better visual outcome is reported with ONSF after surgery for acute rather than chronic papilledema. Thus, patients with BIH and vision threatening papilledema should be offered ONSF without delay. Results are favorable in terms of visual outcome, there is an infrequent need for repeated surgery, and in expert hands the procedure is safe with few intraoperative or postoperative complications and no reported mortality.

\section{REFERENCES}

1. Quincke H. Über meningitis serosa: Sammlung linische vortra 67. Inn M ed 1893;23:655-94.

2. Nonne M. Ü ber falle vom symptomenkomplex 'tumor cerebri' mit ausgang in heilun (pseudotumor cerebri): Ü ber letal verlaufene falle von 'pseudotumor cerebri' mit sektionsbefund. Deutsche Zeitschr für N erven Heilkunde 1904;27:169-216.

3. Foley J. B enign forms of intracranial hypertension: Toxic and otitic hydrocephalus. Brain 1955;78:1-41.

4. CorbettJJ, Thompson HS. The rational management of idiopathic intracranial hypertension. A rch Neurol 1989;46:1049-51.

5. Dandy WE. Intracranial pressure without brain tumor: Diagnosis and treatment. A nn Surg 1937;106:492-513. 
6. Smith JL. Whence pseudotumor cerebri? J Clin Neuroophthalmol 1985;5:55-56.

7. Durcan FJ, Corbett JJ, W all M. The incidence of pseudotumor cerebri: Population studies in I owa and L ouisiana. A rch $\mathrm{N}$ eurol 1988;45:875-77.

8. Wall M, George D. Idiopathic intracranial hypertension. A prospective study of 50 patients. Brain 1991;114:155-80.

9. Digre KB, Corbett J J. Idiopathic intracranial hypertension (pseudotumor cerebri): A reappraisal. Neurology 2001;7:2-67.

10. Fujiwara S, Sawamura $Y, K$ ato T, A be H, K atusima H. Idiopathic intracranial hypertension in female homozygous twins. J Neurol Neurosurg Psychiatry 1997;62:652-54.

11. J ohnston I, M organ M K. A familial coincidence of pseudotumor cerebri and communicating hydrocephalus. Neurosurgery 1991;28:727-29.

12. Donal dson J0. Pathogenesis of pseudotumor cerebri syndromes. Neurology 1981;31:877-80.

13. Sahs $A L$, J oynt RJ . B rain swelling of unknown cause. N eurology 1956;6:791-803.

14. M oser FG, Hilal SK, A brams G, B ello JA, Schipper H, Silver A J. M R imaging of pseudotumor cerebri. A R A m J Roentgenol 1988;150:903-09.

15. Sorensen PS, Thomsen C, G jerris F, Henriksen O. B rain water accumulation in pseudotumour cerebri demonstrated by M Rimaging of brain water self-diffusion. A cta Neurochir Suppl (Wien) 1990;51:363-65.

16. Karahalios DG, Rekate $\mathrm{HL}, \mathrm{K}$ hayata $\mathrm{MH}$, A postolides PJ. Elevated intracranial venous pressure as a universal mechanism in pseudotumor cerebri of varying etiologies. Neurology 1996;46:198-202.

17. Sugerman HJ, Felton WL, Salvant JB Jr, Sismanis A, K ellum $J M$. Effects of surgically induced weight loss on idiopathic intracranial hypertension in morbid obesity. Neurology 1995;45:1655-59.

18. Wall M. The headache profile of idiopathic intracranial hypertension. Cephalal gia 1990;10:331-35.

19. J ohnston I, Patterson A. B enign intracranial hypertension: Part II-CSF pressure and circulation. B rain 1974;97:301-12.

20. Sismanis A. Otologic manifestations of benign intracranial hypertension syndrome: Diagnosis and management. Laryngoscope 1987;97:1-17.

21. Wang SJ, Silberstein SD, Patterson S, Y oung W B. I diopathic intracranial hypertension without papilledema: A case-control study in a headache center. N eurology 1998;51:245-49.

22. Winner $\mathrm{P}, \mathrm{B}$ ello $\mathrm{L}$. Idiopathic intracranial hypertension in a young child without visual symptoms or signs. Headache 1996;36:574-76.

23. Weisberg $L A$. B enign intracranial hypertension. Medicine 1975;54:197-207.

24. Capobianco DJ, B razis PW, Cheshire W P. I diopathic intracranial hypertension and seventh nerve palsy. Headache 1997;37: 286-88.

25. K rishna R, Kosmorsky GS, W right KW. Pseudotumor cerebri sine papilledema with unilateral sixth nerve palsy. J Neuroophthalmol 1998;18:53-55.

26. Scott C , K ardon RH, Lee A G , F risen L, W all M . Diagnosis and grading of papilledema in patients with raised intracranial pressure using optical coherence tomography (OCT) compared to clinical expert assessment using a clinical staging scale. A rch O phthalmol 2010.

27. W all M, George D. V isual loss in pseudotumor cerebri. Incidence and defects related to visual field strategy. A rch Neurol $1987 ; 44: 170-75$
28. Reid A C, M atheson M S, Teasdale G. V olume of the ventricles in benign intracranial hypertension. $L$ ancet 1980;2:7-8.

29. Wessel K, Thron A, Linden D, Petersen D, Dichgans J. Pseudotumor cerebri: Clinical and neuroradiological findings. Eur A rch Psychiatry N eurol Sci 1987;237:54-60.

30. Brodsky $M C, V$ aphiades $M$. M agnetic resonance imaging in pseudotumor cerebri. Ophthalmology 1998;105:1686-93.

31. Gass A, B arker G , Riordan-Eva P, M acM anus D, Sanders M, Tofts PS, et al. MRI of the optic nerve in benign intracranial hypertension. Neuroradiology 1996;38:769-73.

32. Fishman RA. Cerebrospinal fluid in diseases of the nervous system. Philadel phia: W B Saunders Co. 1992.

33. Kupersmith M J, Gamell L, Turbin R, Peck V, Spiegel P, W all $M$. Effects of weight loss on the course of idiopathic intracranial hypertension in women. Neurology 1998;50:1094-98.

34. W ong R, M adill SA, Pandey P, Riordan-Eva P. Idiopathic intracranial hypertension: The association between weight loss and the requirement for systemic treatment. B M C Ophthal mol 2007;7:15.

35. Sugerman HJ, Felton WL III, Sismanis A, K ellum J M , DeM aria EJ, Sugerman EL. Gastric surgery for pseudotumor cerebri associated with severe obesity. A nn Surg 1999;229:634-40.

36. Rubin RC, Henderson ES, O mmaya AK, W alker M D, Rall DP. The production of cerebrospinal fluid in man and its modification by acetazolamide. J Neurosurg 1966;25:430-36.

37. M cC arthy KD, Reed DJ. The effect of acetazolamide and furosemide on CSF production and choroid plexus carbonic anhydrase activity. J Pharmacol Exp Ther 1974;189:194-201.

38. Wall M. Idiopathic intracranial hypertension. Neurol Clin 2010;28(3):593-617.

39. Shah VA, Fung S, Shahbaz R, Taktakishvili O, W all M, L ee A G. Idiopathic intracranial hypertension. Ophthalmology 2007; 114:617.

40. Liu GT, Glaser JS, Schatz NJ. High-dose methylprednisolone and acetazolamide for visual loss in pseudotumor cerebri. A m J Ophthalmol 1994;118:88-96.

41. Corbett JJ. The 1982 Silversides lecture. Problems in the diagnosis and treatment of pseudotumor cerebri. Can J Neurol Sci 1983; 10:221-29.

42. Johnston I, Paterson A, B esser $M$. The treatment of benign intracranial hypertension: A review of 134 cases. Surg Neurol 1981;16:218-24.

43. J ohnston I, B esser M, M organ M K. Cerebrospinal fluid diversion in the treatment of benign intracranial hypertension. J N eurosurg 1988;69:195-202.

44. Rosenberg ML, Corbett JJ, Smith C, Goodwin J, Sergott R, Savino P, Schatz N . Cerebrospinal fluid diversion procedures in pseudotumor cerebri. Neurology 1993;43:1071-72.

45. Eggenberger ER, M iller NR, V itale S. L umboperitoneal shunt for the treatment of pseudotumor cerebri. Neurology 1996;46:1524-30.

46. Kang S. Efficacy of lumbo-peritoneal versus ventriculoperitoneal shunting for management of chronic hydrocephalus following aneurismal subarachnoid hemorrhage. A cta $\mathrm{N}$ eurochir (Wien) 2000;142:45-49.

47. Kulkarni AV, Chumas PD, Drake JM, Armstrong DC. The reliability of the absent cistern sign in assessing $L P$ shunt function. Can J Neurol Sci 1999;26:40-43.

48. Billson FA, Hudson RL. Surgical treatment of chronic papilledema in children. Br J Ophthal mol 1975;59:92-95.

49. Davidson SI. A surgical approach to plerocephalic disc edema. Trans Ophthalmol Soc UK 1969;89:669-90. 
50. Davies G, Zilkha KJ. Decompression of the optic nerve in benign intracranial hypertension. Trans Ophthalmol Soc UK 1976;96:427-29.

51. Brourman ND, Spoor TC, Ramocki JM. Optic nerve sheath decompression for pseudotumor cerebri. A rch Ophthalmol 1988;106:1378-83.

52. Corbett JJ, Nerad JA, Tse DT, A nderson RL. Results of optic nerve sheath fenestration for pseudotumor cerebri: The lateral orbitotomy approach. A rch O phthalmol 1988;106:1391-97.

53. Sergott R C, Savino PJ, B osley TM . M odified optic nerve sheath decompression provides long-term visual improvement for pseudotumor cerebri. A rch Ophthalmol 1988;106:1384-90.

54. Spoor TC, Ramocki J M , M adion M P, W ilkinson M J. Treatment of pseudotumor cerebri by primary and secondary optic nerve sheath decompression. A m J Ophthalmol 1991;112:177-85.
55. Spoor TC, M cH enry J G. L ong-term effectiveness of optic nerve sheath decompression for pseudotumor cerebri. A rch O phthalmol 1993;111:632-35.

56. Sergott RC, Cohen M S, Bosley TM, Savino PJ. Optic nerve decompression may improve the progressive form of nonarteritic ischemic optic neuropathy. Arch Ophthalmol 1989;107: 1743-54.

57. Sergott RC. Optic nerve sheath decompression: History, techniques, and indications. Int Ophthalmol Clin 1991;31: 71-81.

58. Plotnik J L, Kosmorsky GS. O perative complications of optic nerve sheath decompression. Ophthal mology 1993;100:683-90.

59. Gupta A K, Gupta A, Kumar S, Lal V. Endoscopic endonasal management of pseudotumor cerebri: Is it effective? Laryngoscope 2007;117(7):1138-42. 